\title{
DIVERSIFICAÇÃO PRODUTIVA E CONDIÇÕES DE REPRODUÇÃO SOCIAL DE ASSENTADOS RURAIS NO P.A. CHE GUEVARA/CAMPOS DOS GOYTACAZES (RJ)
}

\author{
Priscila Tavares dos Santos ${ }^{1}$ \\ Rodrigo Pennutt da Cruz ${ }^{2}$ \\ Delma Pessanha Neves ${ }^{3}$
}

Resumo: Neste artigo, mediante análise de uma situação empírica, tomamos como objeto uma das alternativas incorporadas pelos assentados do PA Che Guevara para enfrentar os limites impostos por recursos naturais, tornando menos penoso o processo de assentamento em área cujo solo encontra-se altamente degradado em decorrência dos processos produtivos em atendimento às demandas de consumo da agroindústria canavieira. Os assentados se dedicam não somente às atividades agrícolas, mas também as relacionadas a outros setores produtivos, investindo, em muitos casos, na diversificação de alternativas como forma de assegurar a reprodução familiar. Alguns deles complementam o rendimento com a produção de esteiras de tabua, atividade que há muito vem sendo realizada por agricultores e trabalhadores da região, mesmo antes da criação do P.A.. Valorizando as condições diversificadas que possibilitam a reprodução social de famílias de agricultores, destacamos a incorporação de atividades tradicionais, extrativismo com beneficiamento imediato, exercício de compensação diante dos males causados pelo direcionamento da modernização tecnológica com base em agroquímicos.

Palavras-chave: Produção de esteiras; Assentamentos rurais; Campos dos Goytacazes.

${ }^{1}$ Doutora em Antropologia (PPGA/UFF). Email: pris_tavares2000@yahoo.com.br

${ }^{2}$ Doutorando em Antropologia (PPGA/UFF).

${ }^{3}$ Antropóloga e Professora do PPGA/UFF/Bolsista de Produtividade do CNPq/Coordenadora do Programa de Pesquisa: Sistema Sucroalcooleiro: transformações produtivas e reconversão de agentes econômicos./ Coordenadora da coleção Engenhos, usinas, sucatas...? Transformações sociais, agentes produtivos e trajetórias familiares no sistema sucroalcooleiro do estado do Rio de Janeiro. 
Abstract: In this paper, by analyzing an empirical situation, we take as the object of the alternatives built by the settlers PA Che Guevara to meet the limits imposed by natural resources, making it less painful to the settlement process in an area whose soil is highly degraded due production processes in response to consumer demands of the sugarcane industry. The settlers are dedicated not only to agricultural activities but also related to other productive sectors, investing in many cases, the diversification alternatives as a way to ensure family reproduction. Some of them supplement income with the production of plank mats, an activity that has long been held by farmers and workers in the region, even before the PA was created. Valuing the diverse conditions that enable social reproduction of farming families, we highlight the incorporation of traditional activities, with immediate extraction processing, clearing exercise on the harm caused by the direction of technological modernization based on agrochemicals.

Keywords: Production mats; Rural settlements; Campos dos Goytacazes.

\section{Introdução}

Na região de Campos dos Goytacazes, até então marcada pela produção maciça de cana de açúcar e pela concentração da propriedade da terra em mãos de grandes produtores, o processo de redistribuição territorial vem sendo impulsionado pelos trabalhadores (sindicatos, FETAG/RJ) e também pelos reconhecidos porta-vozes dos movimentos organizados de trabalhadores (MST). Como efeito, das 14 usinas no início da década de 1970, somente cinco delas mantiveram-se em exercício, resultando na criação de uma série de assentamentos rurais pelo Incra (cf.: Neves, 1997), como demonstrado na tabela 1.

Destes projetos criados já no final da década de 1990, sete foram constituídos incorporando aproximadamente 301 (trezentas e uma) famílias ${ }^{4}$. Por interações politicamente imprevistas, em alguns desses assentamentos a produção de cana iria colaborar com o objetivo da política nacional de expansão da produção do etanol.

Acompanhar essas transformações a partir do estudo do processo de alterações espacial e social na região torna-se de extrema relevância para a compreensão do sistema de posições sociais construído pelos antigos

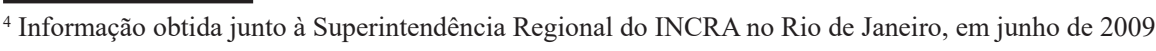

trabalhadores das usinas. Este novo cenário é então formado a partir da extinção da posição de assalariado agrícola e da constituição da categoria agricultor autônomo pela adesão ao projeto de reforma agrária.

Investir na compreensão dos processos sociais que constituíram os assentados rurais que integram o Projeto de Assentamento Che Guevara permitirá pensar essas mudanças em contraposição ao passado, bem como explicitar a subordinação e, em decorrência, a autonomia vividas. Essas questões foram colocadas em evidência por Neves (1981), ao refletir sobre os processos de mudança social entre lavradores e pequenos produtores de cana em condição de subordinação ao mercado de produtos agrícolas. Segundo ela, os modos de percepção do passado são avaliados em relação às condições atuais em que os trabalhadores se encontram submetidos ( NEVES,1981, p.19).

Diante dessas considerações iniciais, neste texto investimos no estudo empírico de assentados rurais situados no Projeto de Assentamento Che Guevara, na região da antiga Fazenda Marrecas, parte da região açucareira do município de Campos dos Goytacazes, estado do Rio de Janeiro.

Tabela 1 - Assentamentos existentes no município de Campos dos Goytacazes - RJ.

\begin{tabular}{cc}
\hline \multicolumn{2}{c}{ PA/ CAMPOS DOS GOYTACAZES } \\
NOME DO PROJETO & 1987 \\
Novo Horizonte & 1997 \\
Zumbi dos Palmares* & 2000 \\
Che Guevara & 2001 \\
Ilha Grande & 2001 \\
Antonio de Farias & 2005 \\
Terra Conquistada & 2005 \\
Dandara dos Palmares & 2005 \\
Santo Amaro & 2006 \\
Oziel Alves I & 2007 \\
Josué de Castro
\end{tabular}

Tabela elaborada com apoio em dados colhidos junto a Superintendência Regional do INCRA, em junho de 2009.

(*) Assentamento localizado em dois municípios: Campos dos Goytacazes e São Francisco do Itabapoana. 
O trabalho de campo foi realizado em 2010 como parte do projeto de pesquisa ${ }^{5}$ Sistema de produção sucroalcooleira: transformações sociais, agentes produtivos e trajetórias familiares, vinculado à linha de pesquisa Mudança e Reprodução Social no Campesinato, ao qual integramos com fins de elaboração de dissertação de mestrado apresentada ao Programa de Pós-Graduação em Antropologia da Universidade Federal Fluminense (PPGA/UFF).

O Projeto de Assentamento Che Guevara é resultado de mobilização de trabalhadores aglutinados por porta-vozes do Movimento dos Trabalhadores Rurais Sem Terra (MST). O processo de assentamento teve início com a desapropriação da Fazenda Baixa Grande, em 1997 e se estendeu até 2007, quando, devido aos problemas de insolvência que afetaram a produção agroindustrial no complexo Baixa Grande, o Incra constatou que aquelas terras deixaram de realizar sua função social. Neves (1997), em estudo sobre o processo de mudança da posição social dos trabalhadores da usina em pequenos produtores agrícolas, demonstra que o processo de desapropriação de terra da usina como resposta aos objetivos da PNRA, na medida em que se configura como resposta particular aos questionamentos levantados, coloca novos problemas para os agentes em questão. Após um ano do início deste processo, líderes do MST organizaram acampamento em torno das terras da fazenda, permanecendo nelas até que as ações se concretizassem e fosse realizado o sorteio para ocupação da terra.

O acampamento foi instalado em 04 de janeiro de 1998 e, pelo projeto, puderam ser assentadas 74 famílias em lotes que variavam em torno de 9,208 a 18,703 hectares. (Mapa 1) Até que o Incra completasse o processo de divisão dos lotes, os líderes do MST estabeleceram uma divisão que provisoriamente definia 10 ha para que as famílias acampadas pudessem dar início às atividades de produção agrícola voltadas ao sustento de seus membros (PEIXOTO, 2001).

As famílias beneficiadas pelo projeto de assentamento são, em grande parte, provenientes de espaços externos à fazenda, tendo em vista que a construção do acampamento em torno do terreno da antiga fazenda foi uma iniciativa desprezada por muitos dos ex-trabalhadores da usina. De acordo com dados obtidos em situação de entrevista, os assentados são oriundos dos estados da Bahia, Espírito Santo, bem como de municípios circunvizinhos ao de Campos dos Goytacazes, como São João da Barra e principalmente São Fidélis. Anteriormente, muitos deles se dedicavam não somente à realização de atividades agrícolas, mas também a outras relacionadas a setores produtivos como, por exemplo, construção civil, marcenaria, mecânica e costura. (Santos, 2014; 2015)

Mapa 1 - Distribuição dos lotes e das áreas de reserva, PA Che Guevara

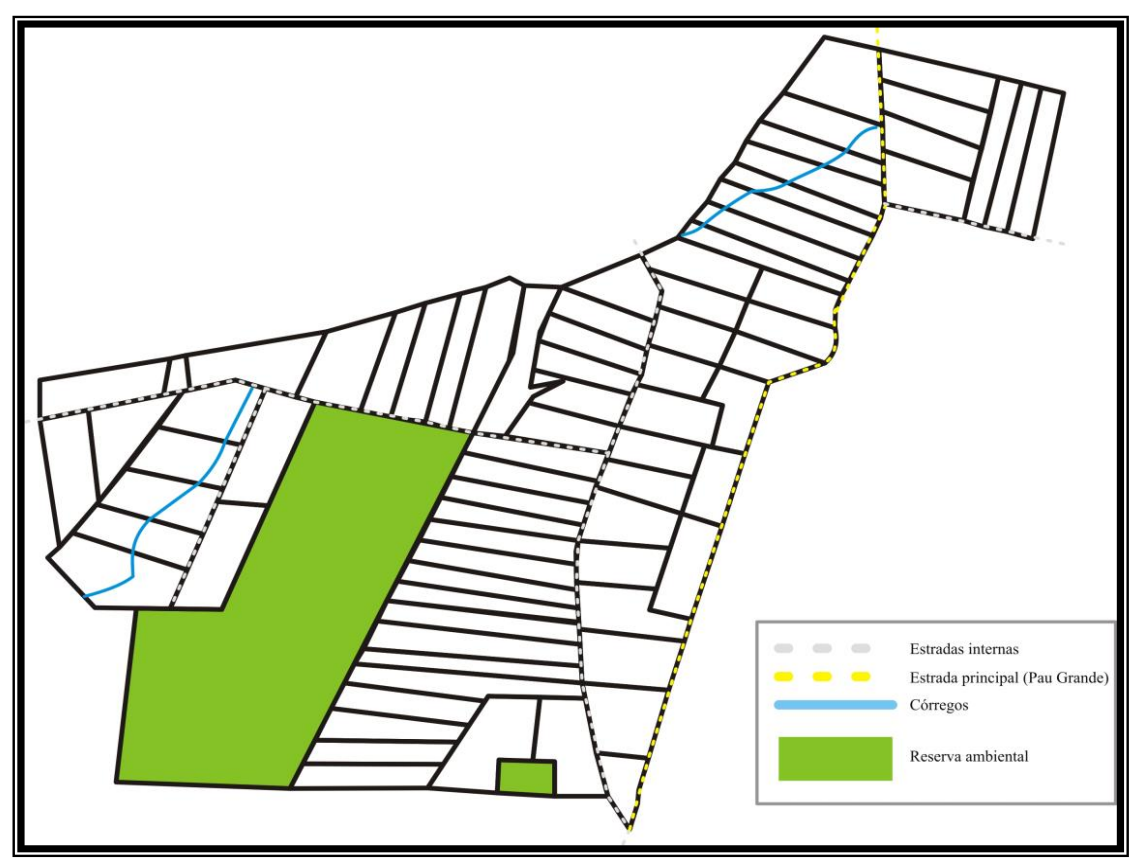

Fonte: Dados levantados a partir de trabalho de campo realizado em fevereiro e agosto de 2010. Mapa elaborado pelos autores (Santos, 2014; 2015; Cruz, 2013).

As famílias beneficiadas pelo projeto de assentamento são, em grande parte, provenientes de espaços externos à fazenda, tendo em vista que a construção do acampamento em torno do terreno da antiga fazenda foi uma iniciativa desprezada por muitos dos ex-trabalhadores da usina. De acordo com dados obtidos em situação de entrevista, os assentados são oriundos dos estados da Bahia, Espírito Santo, bem como de municípios circunvizinhos ao de Campos dos Goytacazes, como São João da Barra e principalmente São Fidélis. Anteriormente, muitos deles se dedicavam não somente à realização de atividades agrícolas, mas também a outras relacionadas a setores produtivos como, por exemplo, construção civil, 
marcenaria, mecânica e costura. (Santos, 2014; 2015)

A partir do rearranjo que se estabeleceu na estrutura fundiária com a desapropriação da fazenda, os trabalhadores se constituíram segundo múltiplas trajetórias de vida ( CRUZ, 2010 ). A despeito dessas múltiplas trajetórias, os assentados rurais ressaltaram as precárias e inadequadas condições para tornarem o lote produtivo e alcançarem o pleno desenvolvimento de práticas produtivas que lhes permitam a manutenção e reprodução social do grupo. Os fatores caracterizados como adversos são sintetizados, quase que por unanimidade, pela degradação do solo, da água ou dos recursos florestais. Os assentados vêem-se diariamente em situação de luta com a natureza local, enfrentando períodos de seca ou de chuvas abundantes.

Diante desse cenário, procuramos compreender o processo de confecção de esteiras de tabua (Typha dominguensis Pers.) como alternativa encontrada pelos assentados do PA Che Guevara, não somente para minimizar os transtornos encontrados no lote, mas enquanto possibilidade de manutenção de uma prática que vem sendo desenvolvida pelos agricultores assentados, apesar das transformações que afetaram a região de Campos dos Goytacazes. Levando em conta as trajetórias individuais dos assentados, tomamo-nas para entender como, sob o prisma da diversidade, uma prática artesanal que perpassa diferentes contextos sociais, econômicos e políticos e cuja a tradição se funde no tempo, visa a assegurar meios de construção social dos assentados. ${ }^{6}$

O processo de produção artesanal de esteiras de tabua na região de Campos dos Goytacazes vem se perpetuando principalmente a partir das antigas famílias de trabalhadores da região. A tabua é localmente reconhecida como um mato (tipo de vegetação reconhecida pelos interlocutores como sem valor econômico e ambiental) uniformente abundante nas terras pantanosas nativas (espaços naturais identificados como lagoas e brejos) e também nos valados e valas ${ }^{7}$ da região. (Foto 1)

Com este recurso, mulheres e crianças confeccionam esteiras que são vendidas aos atravessadores (agentes locais responsáveis pela intermediação do processo de comercialização de produtos agrícolas e demais itens produzidos pelos assentados).

\footnotetext{
Para elaborar esta análise, valemo-nos das seguintes ferramentas de investigação: entrevistas, conversas informais, caminhadas e outras formas que nos permitiram vivenciar as etapas de produção de esteiras.

${ }^{7} \mathrm{O}$ valado é parte de um sistema de captação de água construído pelos administradores da usina. Representa uma vala de nível abaixo do solo por onde a água desviada dos canais do Colégio, São Bento e Andresa chegavam até às fazendas. As valas são de menores proporções, mas destinam-se à mesma atividade.
}

Foto 1 - Área de colheita da tabua, Capão Redondo, Campos dos Goytacazes $(\mathrm{RJ})$

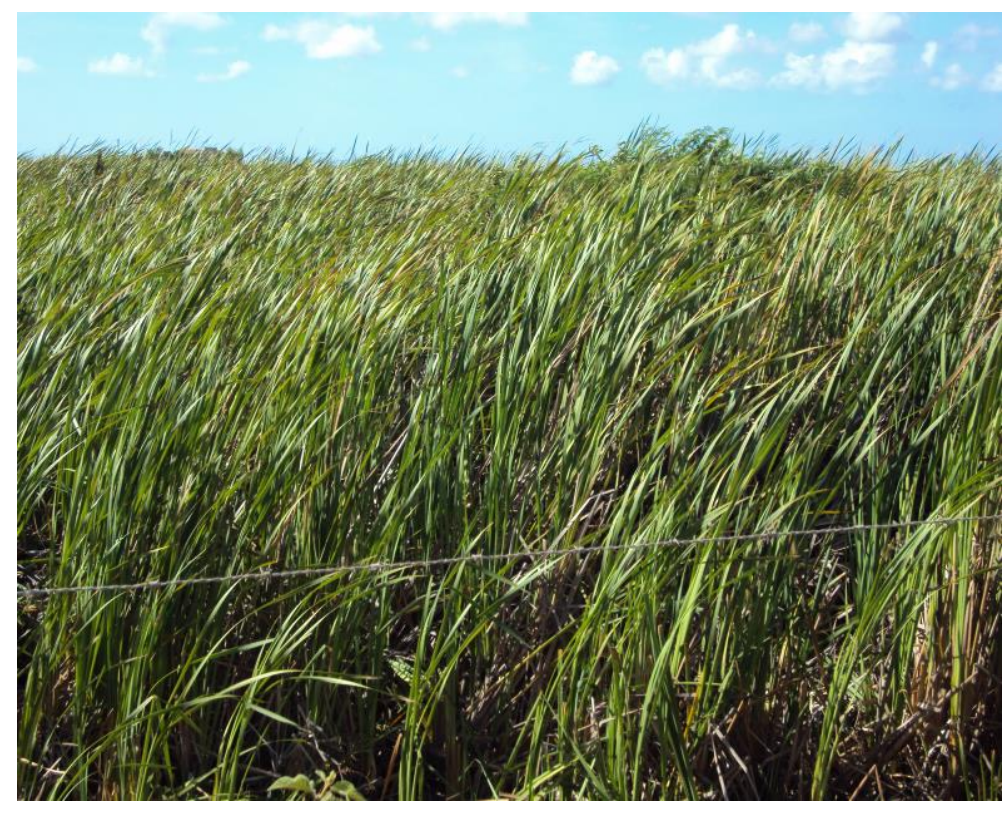

Fotografia de Priscila Tavares dos Santos. Fevereiro de 2010.

Com este recurso, mulheres e crianças confeccionam esteiras que são vendidas aos atravessadores (agentes locais responsáveis pela intermediação do processo de comercialização de produtos agrícolas e demais itens produzidos pelos assentados). Estes, por sua vez, distribuem-nas por diversas redes de comercialização existentes na região do entorno (Marrecas, Bajuro, Água Preta, Barra do Açu) e também aquelas estabelecidas em outros estados (Belo Horizonte, São Paulo e Paraná).

Os valados e valas mostravam-se, na maior parte dos lotes visitados, secos e/ou assoreados ou ainda, em alguns casos, tomados pela tabua e utilizados para a plantação de bananeiras. Em relação a este aspecto, um dos assentados no PA Che Guevara, mostrou como é possível caminhar sobre o leito do rio quando tomado por esta vegetação.. Afirmou ele que o fato de as tabuas tomarem este espaço é o motivo pelo qual "o rio não rompe a água pelas valas que construiu com sua draga".

A prática da produção de esteiras de tabua deixa revelar a rede de relações sociais tecidas por núcleos familiares, bem como as posições ocupadas por cada um dos membros no processo de formação do rendimento mantenedor 
do sustento familiar. Neste sentido, as diferenças existentes no trabalho do chefe (familiar) e na ajuda dada pela mulher e filhos mais novos perpassam o destino dado ao dinheiro recebido com a venda do produto.

A divisão de tarefas segundo relações de gênero na unidade familiar, tal como também é analisada por Neves (1981) ao considerar os vizinhos produtores de cana, referencia as mulheres às atividades desenvolvidas junto ao terreno ou ao quintal; enquanto que aos homens, cabe o preparo da terra e dos espaços mais afastados da residência.

O processo de produção das esteiras pressupõe o estabelecimento de relações materiais e imateriais dos homens com a natureza; a incorporação às forças produtivas um componente subjetivo que permite ao sujeito agir sobre a natureza, dotando-a de inteligibilidade mediante um trabalho das ideias que permite o seu ordenamento e sua transformação ( GODELIER, 1974 ). As condições de possibilidades encontradas pelos assentados rurais para se reproduzirem no lote necessitam de um esforço consciente que viabilize a exploração dos recursos encontrados no lote.

A produção de esteiras não pode ser entendida no sentido de uma construção de uma tradição do patrimônio material e familiar de assentados rurais, mas como reordenamento e coalizão em resposta às relações estabelecidas com os fatores de produção. O conhecimento que permite a construção dos espaços locais mediante a colocação em ação desse conjunto também atribui significados a cada um de seus elementos, correspondendo a modos específicos de agir sobre a natureza e de construção de relações sociais.

Ao valorizar a produção de esteiras enquanto um processo intermitente e realizado por grupo de assentados chamamos atenção para a contingencialidade desse processo. E, nesse sentido, nos aproximamos do que Godelier (1974) denominou de reprodução ampliada, ao romper com a noção de fixidez e de imutabilidade da condição social desses agentes. Esta forma de conhecimento dos assentados, própria ao processo de produção de esteiras, é marcada pela incorporação contínua de novos elementos.

Também refletindo sobre o processo de diversificação de estratégias por produtores agrícolas, Woortmann e Woortmann (1997) afirmaram que o saber técnico é mais que um conhecimento especializado porque é fruto de um modelo mais amplo de percepção da natureza e dos homens e, em sendo assim, não é uníssono. O saber dos assentados possui múltiplas facetas e responde a diversas questões e imposições do meio (natural e social) do qual fazem parte. É um conhecimento específico porque relacionado a um conjunto particular de recursos, homens e instrumentos de trabalho, correspondendo a necessidades também específicas do grupo. No caso aqui valorizado, é um saber que viabiliza a produção de um recurso que seguirá por vias diversas e que se constitui a partir da busca por formas alternativas de reprodução social em um espaço reconhecidamente precarizado de recursos e de possibilidades de inserção produtiva.

Diante disso, nosso investimento no estudo do processo de realização desta atividade prática pelos assentados é no sentido de reconhecer que a região é palco de apostas e de investimentos frente a constrangimentos, mas também a circunstâncias que limitam o investimento nessas alternativas. Indiretamente, esperamos oferecer uma contribuição para uma reflexão menos preconcebida no campo de debate sobre reforma agrária.

\section{Condições de constituição na posição de assentado}

Os fatores fundamentais, no caso desse assentamento, para entender as condições de possibilidade de constituição na posição de assentado, se impõem pelo estudo dos limites existentes para o uso dos fatores de produção. ${ }^{8}$ Limites intervenientes pelas condições de solo e de clima, pela distância em relação aos mercados e, neste caso, também pelas restrições de consumo entre os moradores dos povoados vizinhos. Os limites para o uso dos recursos são ainda decorrentes dos modos de exploração dos fatores de produção adotados pela administração da usina, que até recentemente explorava as atividades agrícolas na fazenda, como considerei anteriormente.

As alternativas da produção agrícola e pecuária possíveis aos produtores assentados, no período do trabalho de campo, compreendiam uma gama limitada de sistemas produtivos, mas ainda variável segundo o tempo de permanência do produtor no lote. Todavia, com maior ou menor extensão, em diversos lotes foram encontrados cultivos dos seguintes produtos, para consumo próprio ou circulação no mercado: abóbora, aipim, quiabo, feijão, jiló, banana, cana, coco, figo, goiaba, graviola, laranja, limão, manga, melão, milho, pinha e eucalipto.

Tomando como uma de suas questões empíricas as relações de trabalho familiar entre agricultores do nordeste do país, Beatriz Heredia (1979) demonstra que os produtos agrícolas são classificados pelos produtores

${ }^{8}$ Para uma análise mais detalhada das estratégias de diversificação produtiva e de comercialização da produção adotadas pelos assentados para construção de projeto de reprodução social, ver Santos (2014) 
sob diferentes formas. Uma delas diz respeito à orientação que os agentes atribuem ao produto: se para consumo ou para comercialização. No primeiro caso, se estão no roçado, os produtores distinguem as verduras e legumes; mas também podem ser reagrupados, segundo a participação na composição das refeições diárias. Se comercializados, os produtores estabelecem novas classificações, considerando sua venda direta ou a partir do seu processamento. Há bastante aproximação dos dois grupos pesquisados, embora os termos sejam relativamente distintos.

Entre os assentados, havia um grande número que mantinha a orientação produtiva referenciada à circulação mercantil dos produtos e que se dedicava ao cultivo da cana e à criação de gado. Alguns agregavam à produção mercantil o cultivo de quiabo e/ou de coco. Raros eram os casos em que os produtores não mantinham cultivos agrícolas ou abriam mão de quaisquer dessas alternativas.

Vale a pena ressaltar que as variedades de produtos agrícolas e de animais para a criação são decorrentes da compra e de laços vicinais de solidariedade, mas também do conhecimento de uma rede de comercialização de proximidade. Tomando como objeto as relações de troca entre vizinhos, Abélès (1983) afirma que tais relações vicinais, que são vistas como complementares, favorecem a reintegração de práticas de troca e estimulam a atribuição de eficazes valores destinados às mercadorias. E, além disso, como considera, permitem a organização espacial mediante consolidação de relações sociais e políticas entre os sujeitos. No caso do Assentamento Che Guevara, as relações de vizinhança facilitadas pela proximidade dos lotes representam, nessa perspectiva, um conjunto de constrangimentos objetivos, nos quais a regularidade das relações de sociabilidade não depende da fixação de uma ordem preestabelecida, tendo em vista a existência de formas de controle, mas, antes de tudo, de modo a não criar diferenciações de bens e de prestígios marcantes entre os assentados.

Assim, os sistemas produtivos privilegiados por esses produtores podem, em grande parte, ser entendidos como respostas coletivas às condições socioeconômicas e ambientais nas quais se instalaram. Trazem à tona não apenas desafios generalizados, mas também decorrentes de outras formas de concorrência em jogo nesse contexto, inclusive entre os próprios assentados.

\section{Produção de esteiras: processos extrativistas e produtivos} da tabua
Para o artesanato das esteiras é necessário conhecer bem a tabua e a diferenciação entre os dois tipos localmente reconhecidos: a tabua vermelha e a tabua branca. Segundo afirmaram os entrevistados, o bom conhecedor retira apenas a tabua vermelha porque esta é mais macia, boa e, sendo considerada como de melhor manuseio menos prejudicial aos artesãos. A variedade branca, como consideraram, a supera em quantidade nos brejos e alagados existentes no assentamento. Segundo afirmaram a tabua branca é de palha lisa, ruim, fraca e não serve para fazer uma boa esteira.

O processo de colheita da tabua é, segundo os assentados, uma atividade de risco e penosa, relativamente as demais práticas produtivas que realizam, como é o caso da atividade agrícola e a produção de doces em compotas. Nos espaços onde a tabua se desenvolve, também podem ser vistos muitas cobras e jacarés, por isso durante a colheita os trabalhadores da planta podem ser picados e mordidos. Outra situação de risco enfrentado pelos coletores de tabua é o terreno lodoso e lamacento que precisam entrar para ter acesso à planta. Foram recorrentes os relatos de assentados que ficaram presos com lama até a cintura, imobilizados, à espera de um familiar para socorrer.

$\mathrm{O}$ trecho e destaque a seguir expressa os fatores intervenientes durante o processo de colheita da tabua pelos assentados.

O melhor horário para sair de casa e pegar a tabua é pela manhã, bem cedo, antes do sol nascer. Pode sair umas seis horas e vai para lá tirar. Mas é melhor sair umas cinco e meia, porque a caminhada dentro da mata de tabua é muito quente. A mata é fechada e abafa muito a gente. Até mesmo para uma pessoa ir sozinha é difícil, porque se passar mal lá dentro pode até morrer... Tem muito bicho: tem cobra, tem jacaré e você pode ser mordido lá e ninguém vê.” (H., assentada PA Che Guevara. Entrevista realizada em fevereiro de 2010)

Como descreveu H., a penosidade e os riscos da colheita tem contribuído para que os homens, membros dos grupos familiares, colaborem neste processo. Essa atividade vem sendo realizada, em muitos casos, por filhos e homens afastados do trabalho agrícola, já que o período diurno vem sendo priorizado como ideal para a realização das atividades nas lavouras, principalmente durante o verão marcado por dias quentes e secos.

Ainda sobre as condições de acesso à tabua, a entrevistada a seguir comenta sobre as vantagens da proximidade do lote em relação aos espaços valorizados de coleta da tabua. 
Naquela época era mais difícil encontrar tabua do que hoje. Hoje é mais fácil, porque todo lugar tem tabua. O senhor vai para lá, para o lado de lá da ponte.... Se o senhor olhar, tem tabua. Tem aos montes lá que o povo tirava. Ali na frente mesmo tem um bocado tirado para o caminhão apanhar... (S., assentada PA Che Guevara. Entrevista realizada em fevereiro de 2010)

Dona S. mencionou que a possibilidade de obtenção das tabuas em distâncias menores foi favorecida principalmente a partir da desativação do sistema de irrigação construído pelos usineiros em atendimento à demanda de água para as lavouras de cana de açúcar. Segundo descreveram também outros entrevistados, esse sistema foi desativado por falta de investimentos dos usineiros e, mais recentemente, pela precariedade das condições financeiras dos assentados em manterem em funcionamento as bombas de irrigação. Assim, com o passar dos anos, os canais vêm paulatinamente enfrentando processos de assoreamento e, com isso, criando condições para o estabelecimento das tabuas nas proximidades dos lotes.

Considerando ainda as condições de produção das esteiras de tabua, chamo-se atenção para a organização da mão de obra familiar. O processo de realização das esteiras de tabua pode ser integrado por cada membro do grupo doméstico. O primeiro momento consiste na colheita do capim (tabua).

Foto 2 - Amarrado de tabua com barbante

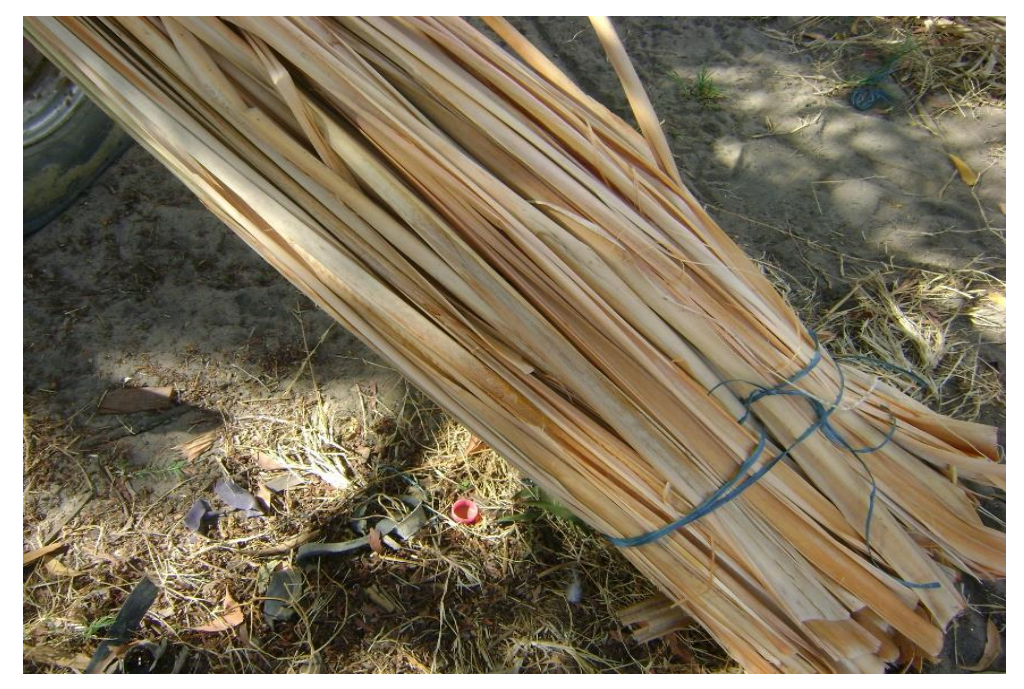

Fotografia de Priscila Tavares dos Santos. Fevereiro de 2010.
Caracteriza-se pelo direcionamento dos homens até as florestas de tabua para cortar as folhas. Com o auxílio de uma faca ou facão (instrumento também utilizado pelos assentados no corte de cana), eles a transportam para o terreiro das casas em amarrados (feixes de folhas de tabua separados em lotes com barbante). Cada amarrado de tabua é organizado de modo que se chega a fazer até três esteiras, considerando-se um tamanho padrão. (Foto 2)

$\mathrm{O}$ transporte dos amarrados de tabua das áreas alagadas até o terreiro da casa pode ser feito com auxílio de carroça puxada por burro e ainda com trator, motocicleta ou caminhão de pequeno porte. As famílias desprovidas de tais utensílios alugam por preço variado algum meio de transporte. Pelo aluguel é pago um valor fixo por viagens realizadas do local da coleta até o lote do assentado. O gasto com o transporte, pouco recorrente entre os assentados, não é incorporado ao valor da esteira, considerando que as demais unidades familiares produtoras possuem carroça própria. Após esta etapa, a tabua é posta de modo espalhado, pelas mulheres ou crianças, no terreiro ou quintal para secar durante um período estimado de quinze dias corridos, visto que depende das condições climáticas locais (intensidade do sol). Quando a tabua está totalmente seca, segue-se o preparo da imbira (ou embira $)^{9}$ que é um cipó feito do miolinho da própria tabua, neste caso, ainda não totalmente seca, mas um pouco verde para evitar que arrebente no momento da amarração da palha de tabua que compõe a esteira. É feita batendo-se bem a tabua ainda verde com o auxílio de um pau de eucalipto. Este não pode ser muito velho porque perde sua resistência, partindo-se durante o processo de socar.

Os feixes já secos de tabua são distribuídos no tear pelos cambitos marcações espaçadas feitas em um pedaço de pau de eucalipto - num total de doze (número variável de acordo com o tamanho desejado da esteira) - e trançados. O tear é um tronco de eucalipto que serve como base para a confecção da esteira. (Foto 3)

Após seu preparo são estocadas. Em alguns casos, quando armazenadas em um cômodo dentro da própria casa, épara evitarnão serem atacadas por formigas; em outros, dentro de galpões fora do espaço da residência, se representam a possibilidade de estabelecimento de ninho de cobras no meio do estoque.

Devido à periculosidade expressada pelas condições de realização do

Além da imbira também podem ser utilizados o barbante e o cordão de plástico (de cor azul ou verde,) vendido em lojas de materiais agrícolas. Neste caso, a escolha da primeira opção confere um valor de comercialização mais elevado ao produto final. 
trabalho, geralmente é realizado pelos homens; contudo, dadas a situação de ausência e a impossibilidade de ajuda pelos maridos, restam às mulheres realizarem-nas, sozinhas ou ainda mediante ajuda dos filhos mais jovens.

Foto 3 - Esteira em processo de confecção com destaque para os instrumentos de trabalho utilizados.

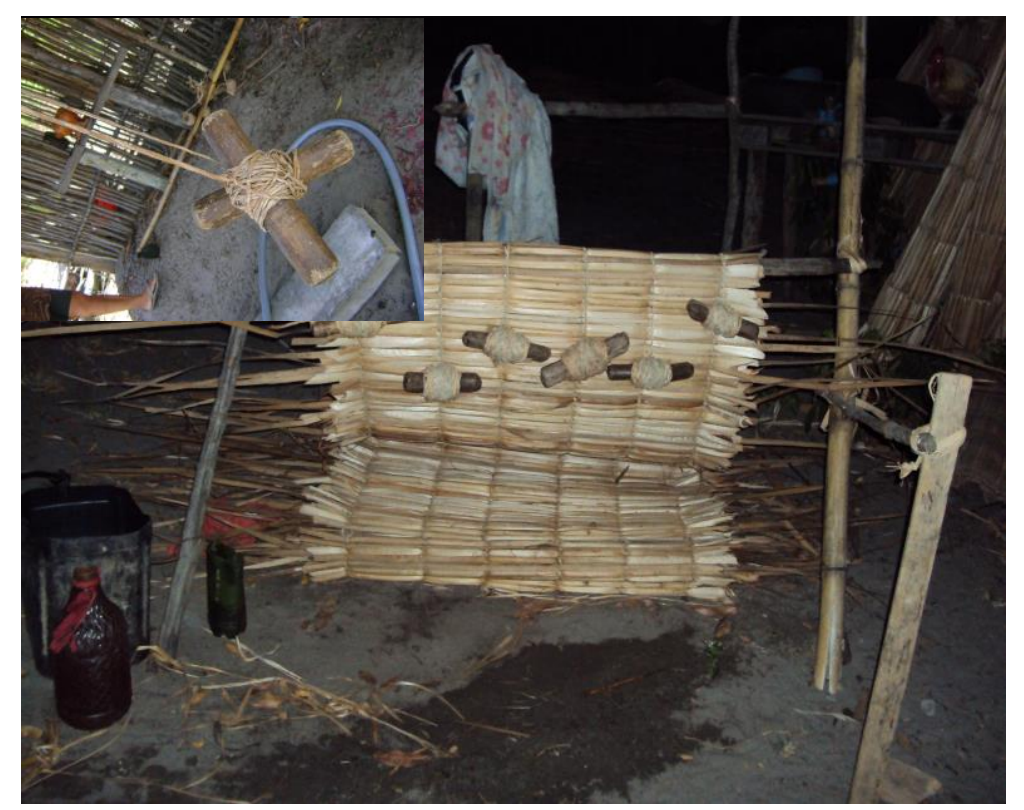

Fotografia de Rodrigo Pennutt da Cruz. Fevereiro de 2010.

Sobre este aspecto, J., conta que, ainda criança e juntamente com seu irmão também pequeno, aprendeu a atividade com sua mãe, acompanhando-a desde o momento da colheita da tabua no brejo. Descreveu:

Eu aprendi com minha mãe. Quando a minha mãe estava coisa, a gente ajudava. No caso, a tabua quem pegava era o meu pai e minha mãe. Eles levavam a gente, mas a gente era muito pequena. Tinha que atravessar rio... e eu era pequenininha. Eles botavam a gente aqui (no ombro) cada um em um... eu e meu irmão... e atravessava o rio. (J., assentada PA Che Guevara. Entrevista realizada em fevereiro de 2010)

Nessa etapa, o papel do homem no preparo das esteiras é marcado pela ambiguidade, visto que, a princípio, é uma atividade quase que exclusivamente feminina e infantil. Contudo, passa pelo apoio do homem no momento da colheita nos terrenos alagados. Após o período de falência das usinas, os homens cuidavam do corte e dedicavam-se a outras etapas do preparo da esteira, dividindo a atividade com a esposa e os filhos.

Ao referir sobre os processos de mudança na organização social local, Dona H., reflete sobre o modelo considerado tradicional de divisão dos papéis no grupo familiar.

Na minha família trabalhavam com esteira. Todo mundo, todo mundo. Os homens antigamente também faziam esteira, pegavam caminhão de tabua pra vender... Foi assim quando eu comecei. Para fazer uma esteira era assim: primeiro, você vai lá no brejo, porque ela dá dentro da lama, onde pisa o pé e vai embora. Corta ela, põe no caminhão e trás pra casa. Chega em casa, abre folha por folha e espalha ela e põe pra secar. Depois que tiver seca, você junta ela. Aí você pega uma ainda verde e bate para formar o cordão que trança ela (embira). Aí você corta uma madeira fina para fazer o cambito... São doze, né: um do lado do outro para jogar. E torce a embira e coloca. É meio difícil de explicar.... (H., assentada PA Che Guevara. Entrevista realizada em fevereiro de 2010)

Durante o período de realização do trabalho de campo, o que observamos é que a confecção de esteiras é prática predominante feminina, principalmente durante as atividades do Complexo Agrícola. Os chefes dos núcleos familiares e seus filhos mais novos saíam para o trabalho nas lavouras de cana e os demais membros dedicavam-se a realização de tal exercício. Porém, naqueles locais mais afastados das usinas, esta atividade era primariamente exercida pelos homens, inclusive constituindo-se em fonte de renda da família.

A esteira de tabua é objeto de múltiplas aplicações, tanto na perspectiva daqueles que estão diretamente envolvidos no processo de produção, quanto daqueles indiretamente beneficiados. As esteiras serviam de proteção das cargas transportadas por caminhões, como sela no dorso de burros e cavalos, como cama e telhado das construções, dentre outras funções. Sobre este último aspecto, uma entrevistada, residente no assentamento desde o início do processo de assentamento valorizado como tempo do acampamento (condição esta valorizada pela maioria dos assentados que enfrentaram as dificuldades para acesso à terra) descreveu uma dessas possibilidades de utilização desse produto: 
Nós estamos aqui desde as barracas. Chegamos igual a um mendigo! Nós dormíamos em barraca de esteira. A parede de esteira, fazia a cama de pau e dormia ali. Essa esteira que o pessoal... Todo mundo aqui fazia esteira. A gente comprava para montar o acampamento porque não tinha jeito. A gente comprava... era um realzinho e fazia parede de esteira, fazia teto. Botava um plástico quando estava chovendo para não molhar muito dentro do barraco. Igual quando era criança que brincava de casinha. (N., assentada PA Che Guevara. Entrevista realizada em fevereiro de 2010)

$\mathrm{O}$ trecho acima valoriza as condições de precariedade enfrentadas pelas famílias acampadas anteriormente ao processo de divisão dos lotes pelo Incra. $\mathrm{O}$ enfrentamento das intempéries da natureza e o acesso aos demais recursos fundamentais à sobrevivência no acampamento eram viabilizados por mecanismos de solidariedade entre eles, com troca de utensílios de uso doméstico e, principalmente de esteiras prioritariamente destinadas ao uso de crianças e idosos.

No que tange aos destinos comerciais das esteiras o escoamento da produção é intermediado pelo papel do atravessador. Durante o período de realização das entrevistas, o preço pago pelo mediador oscilava entre um real e setenta centavos cada esteira. Em geral, objetivando condições mais favoráveis de obtenção de rendimento, as assentadas acumulavam a produção quinzenal para comercialização. O comprador busca as esteiras com um carro dotado de carroceria, fazendo o pagamento à vista do valor correspondente ao total das esteiras produzidas no lote. Conforme informações obtidas durante as entrevistas, não há casos de encomendas; o estoque é arrematado em sua totalidade e, algumas vezes, podendo ultrapassar uma centena. Questionados sobre a absorção da produção local de esteiras, um dos atravessadores afirmou que a demanda é grande principalmente durante os meses do verão, sendo utilizadas por veranistas e frequentadores de casas de praia em municípios próximos. Nesses períodos, chegam a ser revendidas por quinze a vinte reais a unidade.

O tempo estimado utilizado na produção de uma esteira varia de 12 a 40 minutos, de acordo com a agilidade adquirida com os anos dedicados à atividade e também com os palmos de largura das folhas de tabua colhidas. Chega-se a produzir até 10 esteiras diariamente. De acordo com F. e Dona H., ambas reconheceram ter aprendido a atividade com seus avós e pais quando ainda crianças, mencionaram que a comercialização das esteiras ao atravessador depende da produção conforme os padrões de consumo preferenciais. O tamanho ideal das esteiras, nesses casos, corresponde às seguintes proporções métricas: oito palmos de largura e um metro de comprimento $(2,00 \times 1,00 \mathrm{~m})$.

Refletindo sobre as condições de comercialização das esteiras, afirmou Dona N.:

O tamanho da esteira varia. A esteira é $1,80 \mathrm{~m}$ com seis costuras. Tem uma de dez costuras, que é um $1,80 \mathrm{~m}$ de altura $\mathrm{x} 1,50 \mathrm{~m}$ de comprimento. São os clientes que pedem a metragem. Mas essas eram para uso doméstico. Para transporte era $0,40 \mathrm{~m} \times 1,00 \mathrm{~m} \ldots$ a das empresas do transporte. A esteira é fina era para transporte. A esteira mais grossa, para uso doméstico. A diferença de preço é que a mais grossa era mais cara. (N., atravessador. Entrevistado em fevereiro de 2010)

As esteiras produzidas fora do padrão para atendimento ao consumo doméstico - principalmente veranistas - são reconhecidas outras formas de utilização e, nesses casos, com preços também secundarizados. Cabe ressaltar que a produção de esteiras fora desses padrões, contudo, não impõe ao assentado a perda do tempo investido na sua confecção, tendo em vista que o atravessador incorpora qualquer tamanho de esteira produzida. Comparativamente ao tempo gasto nas atividades das lavouras em condições desfavoráveis de recursos naturais, como sinalizamos anteriormente, a prática da produção de esteiras corresponde ao que Galeski (1972) valorizou como a relação de equilíbrio entre o esforço realizado e a demanda de consumo familiar. Neste sentido, as perdas impostas pelas intempéries às lavouras agrícolas foram incorporadas ao cálculo realizado pelos assentados ao considerarem a gestão da força de trabalho familiar. Cabe ainda mencionar que durante a realização do trabalho de campo, os assentados enfrentavam um período marcado pela seca que, segundo eles, não haviam experimentado desde o momento em que participaram do acampamento. Os moradores mais antigos, mormente aqueles que integravam o sistema agroindustrial como trabalhadores das fazendas, mencionaram que há décadas não enfrentavam período de estiagem tão grande.

Segundo avaliação dos entrevistados, a renda obtida com a venda das esteiras era revertida para consumo interno da família, mediante compras necessárias ao dia-a-dia. Entretanto, esta é uma fonte de renda complementar para a maioria das famílias, caracterizando-se como ajuda em situações de 
despesas emergenciais e mais imediatas. Em média, cada família que produz esteiras, vendendo por um real e setenta centavos cada, no fim do mês, descontando o transporte, pode ganhar cerca de quinhentos e vinte reais. $\mathrm{O}$ que, de certa forma, representa um valor significante para a renda familiar.

Este cálculo faz parte das práticas relacionadas aos produtores agrícolas, não como algo percebido pela presença de uma possível racionalidade econômica capitalista, mas uma lógica onde as estratégias de reprodução familiar não passam exclusivamente pela ótica produtiva como valor de ganho (Leite et. al, 2004), mas sim com a presença de mão de obra do chefe do núcleo familiar (marido), principal responsável pelas decisões tomadas para o andamento da produção da família, divisão consagrada por Chayanov (1981).

\section{Algumas considerações}

As estratégias de diversificação produtiva adotadas e as experiências valoradas no decorrer do processo de constituição de assentado são compreendidas enquanto alternativas contextuais e possíveis de uso de recursos naturais nesse ambiente. Algumas delas são dependentes da composição, do ciclo de vida e da distribuição sexual do grupo familiar, mas também da presença ou da ausência de dependentes perenes, fatores que interferem na alocação de recursos produtivos no lote e na agregação de situações de crédito e assalariamento. Da articulação desses fatores, alguns assentados valorizaram a autonomia alcançada a partir da superação ou do enfrentamento de constrangimentos relativos, todavia diferenciando a produção agrícola familiar.

Tomar o processo de produção de esteiras de tabua como objeto de análise, pode ser considerado de extrema relevância para compreensão das transformações ocorridas na região nos últimos anos. Apesar de estas terem marcado rupturas sociais (falências das usinas e criações de assentamentos rurais), a prática de confecção dessas esteiras continua presente na obtenção de renda para manutenção do núcleo familiar. Evidentemente algumas mudanças ocorreram, como a entrada maciça da figura masculina no preparo do artesanato, não mais se limitando apenas à colheita da tabua. Contudo, em alguns momentos, principalmente no período que antecede à criação do assentamento (momento crítico, onde não havia mercado de trabalho para estes) confeccionando-as junto com toda a família.

Posteriormente ao período de implementação do projeto de assentamento, a produção de esteiras continua presente, concomitantemente a outras práticas produtivas que igualmente contribuem para a composição dos rendimentos internos dos grupos familiares ali contemplados. A importância da ajuda que muitos assentados mencionaram correspondeu a graus diferenciados de obtenção de rendimento e, segundo apontaram, nos períodos considerados críticos da produção (tais como aqueles impostos pela seca prolongada), a produção de esteiras de tabua tem se constituído enquanto atividade fundamental para assegurar a reprodução social das famílias.

Ao refletirmos sobre a produção de esteiras enquanto uma das possibilidades de constituição de vínculos pelos assentados, buscamos valorizar as diferentes práticas produtivas que esses produtos elegem para corresponderem aos objetivos da política de reforma agrária no país. Entretanto, o papel que desempenham, tanto na produção de gêneros alimentícios quanto no desempenho de outras atividades produtivas, correspondem aos inúmeros investimentos e à capacidade criativa desses agentes. Pensados a partir deste prisma, cabe-nos reconhecê-los enquanto peça fundamental à continuidade dos projetos de assentamento rural no país.

Analisar as condições de reprodução desses agricultores também se torna fundamental para refletir alguns dos termos em que processos de assentamento são colocados em prática, no bojo do Programa Nacional de Reforma Agrária. Os dados por ora apresentados trazem à tona uma das mais importantes questões para se compreender os investimentos que os assentados realizam nas respectivas unidades de produção, haja vista que estas dependem, basicamente, do tempo de permanência no lote e da variedade de produtos cultivados e de criações. Se a permanência no lote é fundamental para o assentado atingir a relativa eficiência dos sistemas produtivos, a variedade e associação desses sistemas são resultantes do conhecimento que o produtor desenvolve, ao longo do tempo, no trato com os recursos naturais que ele for capaz de conhecer e de financeiramente se apropriar.

\section{Referências bibliográficas}

ABÉLÈS, Marc. Le lieu du politique. Paris: Société d'Ethnographie, 1983. BERGAMASCO, Sonia Maria Pessoa Pereira. A realidade dos assentamentos rurais por detrás dos números. Estudos Avançados, n. 11, v. 31, p. 37-49, 
1997.

CHAYANOV, Alexander. Sobre a teoria dos sistemas econômicos não capitalistas. São Paulo, Brasiliense, 1981.

CRUZ, Rodrigo Pennutti. ASSENTADO E ASSENTADOS: formas de diferenciação entre agricultores no Projeto de Assentamento Che Guevara (Campos dos Goytacazes/RJ). Dissertação [Mestrado em Antropologia]. Programa de Pós-Graduação em Antropologia, Universidade Federal Fluminense, Niterói, 2013.

HERÉDIA, Beatriz Maria Alásia de. A morada da vida. Trabalho familiar de pequenos produtores no nordeste do Brasil. Rio de Janeiro: Paz e Terra, 1979.

LEITE, Sérgio; HEREDIA, Beatriz (et. al). Impactos dos assentamentos: um estudo sobre o meio rural brasileiro. Brasília: NEAD; São Paulo: Ed. UNESP, 2004.

DE LUCA, Mônica Maria Barbosa Leiva. Histórias de identidades num assentamento rural. ETD, Campinas, v. 4, n. 1, p.10-31, dez. 2002.

GALESKI, Boguslaw. Basic concepts of rural sociology. Manchester: University Press, 1972.

NEVES, Delma Pessanha. Lavradores e Pequenos Produtores de Cana. Estudo das formas de subordinação dos pequenos produtores agrícolas ao capital. Rio de Janeiro: Zahar, 1981.

Reforma Agrária em Migalhas. Niterói: EDUFF, 1997.

Reforma agrária esforçada. In: Simpósio Impasses e Dilemas da Política de Assentamentos - balanço de 20 anos. São Paulo. Simpósio Impasses e Dilemas da Política de Assentamentos - balanço de 20 anos. São Paulo: UNIARA, 2005.

PEDLOWSKI, Marcos Antonio Pedlowski et al. Os Limites da Reforma
Agrária Desassistida na Região Norte do Estado do Rio de Janeiro: Entre o Descaso do Estado e a Resistência dos Assentados. XIII Congresso Brasileiro de Sociologia. Recife: UFPE, 2007.

SANTOS, Priscila Tavares dos. A luta com a terra no assentamento Che Guevara (RJ): produção e transmissão de conhecimentos entre assentados. [Dissertação]. Mestrado em Antropologia. Programa de PósGraduação em Antropologia, Universidade Federal Fluminense, Niterói, 2011.

SANTOS, Priscila Tavares dos. Luta com a terra na luta pela terra: produção de conhecimento entre assentados do Projeto de Assentamento Che Guevara (Campos dos Goytacazes/RJ). Niterói: Alternativa, 2014.

SAUER, Sérgio. O significado dos assentamentos de reforma agrária no Brasil. In: SPAROVEK, Gerd. e FRANÇA, Caio Galvão de (Coords.) Assentamentos em Debate. Brasília: Nead, 2005: 57-74.

SPAROVEK, Gerd. e FRANÇA, Caio Galvão de (Coords.). A Qualidade dos Assentamentos da Reforma Agrária Brasileira. In: Assentamentos em Debate. Brasília: Nead, 2005: 10-38. 